\title{
PREOPERATIVE REVELATION OF INSULIN RESISTANCE AS A CRITERION OF DEBULKING NECESSITY IN PATIENTS WITH OBESITY
}

\author{
Kostyantyn Mylytsya \\ Department of surgery and proctology \\ State Institution "Zaporizhzhya Medical Academy of \\ Postgraduate Education of the Ministry of Health of Ukraine" \\ 20 Vintera blvd., Zaporozhye, Ukraine, 69096 \\ kmsurgeon@yahoo.com
}

Olga Lavryk

Department of surgery and transplantology

National Medical Academy of Postgraduate Education named after P. Shupyk

9 Dorogozhitskaya str., Kyiv, Ukraine, 02000

olga.lavryk@gmail.com

Andrei Lavryk

Department of Surgery of the Esophagus and Reconstructive Gastroenterology

State Institution "National Institute of Surgery and T

ransplantology named after A. A. Shalimova NAMS Ukraine"

30 Geroev Sevastopolya str., Kyiv, Ukraine, 03680

andriy.lavryk@gmail.com

\begin{abstract}
The article considers the questions of a necessity of widening the list of obligatory preoperative examinations of patients with obesity for the choice of adequate operation volume, especially for simultaneous debulking of a greater omentum. The aim of research is an estimation of possibility of using an insulin resistance index (HOMA - IR) as a necessity criterion of simultaneous debulking of a greater omentum at operative interventions in patients with obesity.

There were examined 60 persons from the surgical stationary, divided in 2 groups. 1 group included 20 patients with the normal body mass, $2-40$ patients with different degrees of obesity. Insulin resistance was revealed on the base of glucose and insulin estimation, HOMA-IR index calculation.

It was revealed, that glucose level in all patients doesn't reliably exceeds the upper threshold of norm, insulin rates don't differ from the control ones, even in patients with obesity, and rise in $20 \%$ of patients only at 3 degree of obesity. It creates an illusion about the normal state of carbohydrate metabolism in these patients, whereas insulin resistance index estimation allows to reveal a pre-clinic stage of these disorders and to make a timely decision as to a possibility and necessity of simultaneous palliative operation as an omentectomy that doesn't complicate a course of operation and postoperational period, but allows to decrease an expressiveness of carbohydrate metabolism disorders at obesity.

The standard preoperative estimation of glucose level in blood doesn't allow to diagnose an insulin resistance state, that is patients of the high risk group of metabolic syndrome development (especially the ones with obesity) need the additional insulin estimation and insulin resistance index calculation in preoperational period.
\end{abstract}

Keywords: insulin resistance, obesity, debulking, volume of preoperative examination.

\section{Introduction}

Among surgical problems the special place is occupied by the ones of simultaneous surgery [1]. It is caused by different factors. First of all it is connected with anesthesiology, reanimatology and surgery achievements. Innovative technologies allow to reduce an operation time essentially, to widen its volume, to realize several operations at one intervention [2]. No less important direction is a palliative surgery that doesn't completely solve all patients' problems but allows to increase their life quality [3]. These operations give a possibility to decelerate or stabilize the pathological processes development, to lighten a patient's state and/or prolong its life. It is a base for 
searching objective predictors of pathological processes development that allow to make a timely decision as to a necessity of simultaneous operative intervention for preventing a hidden or latent disease progression, lightening of a patient's state.

It is well-known, that the ones of most serious comorbidity risk factors are obesity and metabolic syndrome [4]. This combination conditions oncogenesis [5], development of such heavy diseases as diabetes mellitus type 2, stroke, myocardium infarction, fatty hepatosis, associated with osteoarthritis, night apnea, respiratory function disorders and many other diseases, less heavy but also causing invalidism [6]. Hypertonic disease development is also connected with obesity and metabolic syndrome [7].

The accepted criterion of carbohydrate metabolism disorder in literature is an insulin resistance state (IR), diagnosed using HOMA - IR index [8]. Since IR develops at first in endothelial then in muscular then in hepatic and fatty tissue, it is clear that this index reflects the process not in the early stage of its development but testifies to the presence of hidden diabetes type 2 [9].

Today IR role in metabolic syndrome and its vascular complications development as an infraction, stroke, in initiation of chronic inflammation in fatty tissue, production of inflammatory cytokines and tumor necrosis factor is already not doubted. There were also carried out many studies, testifying to the favorable influence of bariatric operations on an insulin resistance state [10]. The effect of bariatric operations is based on the increase of fatty tissue amount that is agreed with the data of 27 studies, indicating the favorable effect of physical exercises on an insulin resistance index [11].

It was proved, that the maximal toxic effect, activator of endothelial dysfunction initiation [12], insulin resistance and diabetes [13], atherosclerotic processes [14] and oncogenesis is a visceral fatty tissue [15]. And omentectomy, due to cytoreduction of metabolically aggressive fatty tissue, favors the decrease of metabolic disorders and stabilization of the process, especially insulin resistance [16]. Simultaneous debulking of visceral fat (omentectomy) at the main surgical operation is a technically easy stage that doesn't load a patient with additional financial costs, doesn't increase a time of staying in a hospital and doesn't burden the course of postoperative period [17]. But if the necessity of simultaneous omentectomy at bariatric operations is doubted [18], because a bariatric operation normalizes a carbohydrate metabolism state itself [19], simultaneous debulking of a greater omentum [20], at widespread and not complicated abdominal operations is grounded and logic because of its palliative effect at subclinical diabetes and carbohydrate metabolism disorders. Nevertheless, necessity criteria of simultaneous palliative debulking of visceral fat are not determined in practical surgery till today; the obligatory estimation of insulin resistance at preoperational stage is not introduced.

\section{Aim of research}

To estimate a possibility of using insulin resistance index (HOMA - IR) as a necessity criterion of simultaneous debulking of a greater omentum at operative interventions in patients with obesity.

\section{Material and methods of research}

60 patients of the surgical hospital were examined. Besides general clinical examinations, they underwent a glucose and insulin level estimation, HOMA - IR, index, height-weight index (Ketele index) calculation, abdomen measuring by a centimeter ribbon. Ketele index (or body mass index, BMI) is calculated as a ratio of a weight in kilograms to a height square in meters: $=\mathrm{kg} / \mathrm{m}^{2}$. Glucose and insulin were estimated in blood plasma after 8-14 hour night fasting. HOMA - IR index was calculated by the formula: glucose fasting ( $\mathrm{mmol} \backslash \mathrm{l})$ multiplied by insulin fasting ( $\mathrm{mc} \mathrm{Un} / \mathrm{ml})$ and divided by 22,5. Diabetes mellitus and terminal states were referred to exclusion criteria. The rest of diseases were not a selective criterion for exclusion.

All patients were divided in two groups, depending on Ketele index. The first group included patients, which body mass was within normative values (didn't exceed 24,9). The second one included 40 patients with different degrees of obesity (Ketele index exceeded 30,0). In their turn, patients of the second group were dived in subgroups: $2 \mathrm{~A}$ - patients with 1 degree of obesity, $2 \mathrm{~B}$ - with 2 degree of obesity and $2 \mathrm{C}$ - with 3 degree of obesity. 
Groups were comparable by age, type and volume of operations. The gender analysis demonstrated women prevalence in both groups. It is possibly connected with a social problem of female population prevalence in the country.

\section{Results of research}

The data about carbohydrate metabolism state of patients of the surgical hospital, admitted because of different planned surgical pathologies are presented in the Table $\mathbf{1 .}$

Table 1

Data about carbohydrate metabolism state of patients of the surgical hospital

\begin{tabular}{|c|c|c|c|}
\hline & Insulin, mcIU/mI & Glucose, mmol/l & HOMA - IR index \\
\hline $\begin{array}{c}\text { Group } 1 \\
n=20\end{array}$ & $8,48 \pm 0,74$ & $4,62 \pm 0,17$ & $1,72 \pm 0,16$ \\
\hline $\begin{array}{c}\text { Group } 2 \\
n=40\end{array}$ & $25,31 \pm 4,31$ & $4,80 \pm 0,14$ & $5,54 \pm 0,99$ \\
\hline $\begin{array}{c}\text { Group 2A } \\
n=6\end{array}$ & $12,69 \pm 0,96$ & $4,71 \pm 0,33$ & $2,65 \pm 0,27$ \\
\hline $\begin{array}{c}\text { Group 2B } \\
n=10\end{array}$ & $16,14 \pm 1,61$ & $4,83 \pm 0,25$ & $3,55 \pm 0,50$ \\
\hline $\begin{array}{c}\text { Group 2C } \\
n=24\end{array}$ & $32,28 \pm 6,82$ & $4,82 \pm 0,20$ & $7,10 \pm 1,57$ \\
\hline
\end{tabular}

It turned out that patients of the first group with the normal body mass had mean blood glucose level, insulin level, and their own indices within physiological norm. Individual parameters of HOMA - IR index of each examined person from this group did not also exceed physiological fluctuations, and the mean index was lower than the upper admissible threshold by $36,3 \%$.

As a whole, only in 5 patients of 40 ones with obesity the level of glucose a bit (unreliably) exceeded the upper admissible threshold. The detail analysis, depending on the obesity degree, demonstrated that the unessential increase of glucose level was observed in 1 patient with 1 degree of obesity, in 1 with 2 degree of obesity and in 3 patients with 3 degree of obesity. All these patients, even ones with 3 degree of obesity, in postoperative period, after pre- and postoperative dietary limitation had glucose indices, correspondent to the normative values.

An insulin level in patients with the normal body mass was by $38,3 \%$ lower than the normative values median $(2,60-24,9)$. And at obesity an insulin level is 3,0 times more than the indices of 1 group $(\mathrm{P}<0,001)$, but at that only by $1,6 \%$ exceeded the upper norm limit. The detail analysis revealed certain features at obesity of different degrees. It turned out, that if at 1 and 2 degree of obesity there were not estimated changes in the mean values of insulin level and glucose level in blood, at 3 degree of obesity the insulin index increased in 3,8 times $(\mathrm{P}<0,001)$. But in this group also the changes of insulin index were observed only in $20 \%$ patients (although they were rather significant, the mean insulin index reached $70,15 \mathrm{mcIU} / \mathrm{ml}$ that 2,8 exceeds the index of upper norm threshold and 8,3 times the index of patients of the first group without obesity). In the rest $80 \%$ of patients with 3 degree of obesity neither hyperglycemia, nor hyperinsulinemia were not observed.

At obesity IR index 3,2 times exceeded the ones of patients of 1 group and was in average 5,54. At that, if at 1 degree of obesity the mean HOMA indices did not reliably exceed the upper norm limit, although they were 1,5 times more $(\mathrm{P}<0,01)$, than the ones of 1 group, at 2 degree of obesity IR index 2,1 times exceeded the control ones $(\mathrm{P}<0,005)$, and at 3 degree of obesity $-4,1$ times $(P \leq 0,001)$.

\section{Discussion of research results}

This study demonstrated that in patients with the normal body mass (diabetes was an exclusion criterion) the levels of insulin and glucose corresponded to the mean physiological parameters. 
The insulin resistance state was not registered in none case. HOMA - IR index in none case exceeded the normative threshold $-2,7$.

The situation cardinally changes in patients with obesity but it was revealed only after not only glucose but also insulin level estimation and insulin resistance level calculation. It is necessary to pay attention to the fact that the mean glucose index corresponded to the physiological values median and absolutely could not direct a doctor on guessing IR presence in these patients. So, the choice of anesthetic support, observation place in postoperative period (intensive care department or recovery room in surgical department), operation method was carried out without taking into account such important factor of early and late complications as insulin resistance. Neither clinical data that testify to the insulin resistance state, nor biochemical disorders in the glucose index, considered for today as the main factor that reflect the carbohydrate metabolism state, practically were not observed. It naturally influenced clinical decisions.

The received data testify to the ones of other scientists about late changes of blood glucose level at carbohydrate metabolism disorders. That is just why it is recommended throughout the world not to limit oneself to determination of a blood hyperglycemia level but to estimate IR and insulin levels.

But it is also not possible to rely on an insulin index. Its mean value is within the normative values. And the individual analysis revealed disorders only in $20 \%$ of patients. That is there were not registered any biochemically significant, reliable changes of insulin level.

At the surface approach there are all grounds for not taking these indices into account and even not guessing IR presence in these patients, and taking into account only diabetes mellitus at making clinical decisions.

But taking into account that fact that IR already develops and progresses at the normal insulin and glucose indices, that it is reflected (already at the expressed stage at insulin resistance of endothelial, muscular tissue, at the stage of insulin resistance development in hepatic and fatty tissue) by not so much the absolute values of glucose and insulin as the disorder of their ratio, and hyperglycemia and hyperinsulinemia develop not only the disturbance of compensating possibilities of an organism, the study of HOMA - IR index was realized.

It turned out that in patients with the normal body mass HOMA - IR index corresponded to the normative values, so testified to the absence of hepatic and fatty tissue IR.

This situation cardinally changes at obesity. It is necessary to pay attention to the fact that if the glucose level in these patients unreliably exceeded the upper norm limit in $12,5 \%$ of cases, and this increase was extremely unessential (that doesn't influence decision making in practical work), the increase of HOMA index, testifying to insulin resistance was observed in $92,5 \%$ of patients. That is at obesity that creates a risk of postoperative thromboembolism, acute coronary failure syndrome, long cumulation of muscle relaxants in fatty tissue and other mortal complications development, insulin resistance that can cause a series of postoperative complications itself, is not diagnosed.

Thus, the received data one more time prove that at the assessment of the state of a patient with obesity, one must not orient only at the absolute values of glucose and/or insulin. Only estimation of their ratio allows to diagnose or to exclude insulin resistance. But to decrease a financial load at the examination in preoperative periodforn patients with the normal body mass and absence of other metabolic syndrome criteria, one may abstain of the deep study of carbohydrate metabolism state.

Certainly it would be desirable to extrapolate this study on patients of other surgical directions (gynecological, traumatological, urological), but these recommendations are especially important in abdominal surgery, because IR revelation at preoperative stage can help to choose a correct and compliant decision about an operation volume. In particular, simultaneous omentectomy that helps to stabilize or decrease carbohydrate dysfunction manifestations at the expanse of cytoreduction of metabolically aggressive visceral fatty tissue may be offered. Debulking of a greater omentum must be considered in this case as a palliative intervention that doesn't cure a patient but decreases a degree of pathological carbohydrate disorders and delays the development 
of clinical manifestations. The timely IR diagnostics will help to start a conservative therapy for diabetes development prophylaxis in proper time.

\section{Conclusions}

1. The standard preoperative estimation of a blood glucose level doesn't reflect carbohydrate disorders and doesn't allow to diagnose an insulin resistance state.

2. Patients with obesity, who form the high risk group as to the development of postoperative lethal complications, must underwent an estimation of not only blood glucose but also insulin with an insulin resistance level calculation in preoperative period.

3. HOMA - IR index is a laboratory criterion of insulin resistance presence and may by a necessity criterion of simultaneous debulking of a greater omentum at operative intervention in patients with obesity.

\section{References}

[1] Dronova, V. L., Dronov, A. Y., Kryuchyna, E. A., Teslyuk, R. S., Lucenko, E. V., Nastashenko, M. Y. (2013). Simul'tannye operacii pri sochetannyh hirurgicheskih i ginekologicheskih zabolevaniyah. Ukrainskyi zhurnal hyrurgii, 2 (21). Available at: http://dronov.com.ua/viewDetail/8/7

[2] Zaporozhan, V. N., Tatarchuk, T. F., Dronov, A. Y., Dronova, V. L., Kryuchyna, E. A. (2013). Simul'tannye operacii pri sochetanii ginekologicheskoy i hirurgicheskoy patologii. Reproduktivnaya endokrinologiya, 3 (11), 7-16. Available at: http://reproduct-endo.com.ua/pdf/11/7_16.pdf

[3] Koshel, A. P. (2014). Cytoreductive (Palliative) operations and reconstructive surgery: pro et contra. Voprosy rekonstruktivnoy i plasticheskoy hirurgii, 4 (51), 6-8. Available at: http://journals.tsu.ru/ uploads/import/1181/files/_4__2014_8.pdf

[4] Ametov, A. S. (2009). Izbrannye lekcii po endokrinologii. Moscow: MIA, 496.

[5] Bjorge, T., Stocks, T., Lukanova, A., Tretli, S., Selmer, R., Manjer, J. et. al. (2010). Metabolic Syndrome and Endometrial Carcinoma. American Journal of Epidemiology, 171 (8), 892-902. doi: 10.1093/ aje/kwq006

[6] Belyaeva, O. D. (2011). Metabolicheskiy sindrom u bol'nyh abdominal'nym ozhireniem: klinicheskie i molekulyarno-geneticheskie aspekty. Saint Petersburg, 377.

[7] Hwang, L. C., Bai, C. H., Sun, C. A., Chen, C. J. (2012). Prevalence of metabolically healthy obesity and its impacts on incidences of hypertension, diabetes and the metabolic syndrome in Taiwan. Asia Pacific Journal of Clinical Nutrition, 21 (2), 227-233.

[8] Salgado, A. L. F. de A., Carvalho, L. de, Oliveira, A. C., Santos, V. N. dos, Vieira, J. G., Parise, E. R. (2010). Insulin resistance index (HOMA-IR) in the differentiation of patients with non-alcoholic fatty liver disease and healthy individuals. Arquivos de Gastroenterologia, 47 (2), 165-169. doi: 10.1590/ s0004-28032010000200009

[9] Dedov, Y. Y., Shestakova, M. V. (Eds.) (2011). Saharnyy diabet. Diagnostika, lechenie, profilaktika. Moscow: MIA, 801. Available at: http://kingmed.info/knigi/Endokrinologia/book_2773/Saharniy_diabet_Diagnostika_llecheni_profilaktika-Dedov_II_Shestakova_MV-2011-djvu

[10] Buchwald, H., Estok, R., Fahrbach, K., Banel, D., Jensen, M. D., Pories, W. J. et. al. (2009). Weight and Type 2 Diabetes after Bariatric Surgery: Systematic Review and Meta-analysis. The American Journal of Medicine, 122 (3), 248-256. doi: 10.1016/j.amjmed.2008.09.041

[11] Grace, A., Chan, E., Giallauria, F., Graham, P. L., Smart, N. A. (2017). Clinical outcomes and glycaemic responses to different aerobic exercise training intensities in type II diabetes: a systematic review and meta-analysis. Cardiovascular Diabetology, 16 (1), 37. doi: 10.1186/s12933-017-0518-6

[12] Chazova, Y. E., Michka, V. B. (2006). Otkrytaya, mnogocentrovaya, randomizirovannaya, nauchno-prakticheskaya programma MINOTAVR: promezhutochnyy analiz rezul'tatov. Kardiovaskulyarnaya terapiya i profilaktika, $2,81-88$. 
[13] Bluher, M. (2010). The distinction of metabolically "healthy" from "unhealthy" obese individuals. Current Opinion in Lipidology, 21 (1), 38-43. doi: 10.1097/mol.0b013e3283346ccc

[14] Pischon, T., Boeing, H., Hoffmann, K., Bergmann, M., Schulze, M. B., Overvad, K. et. al. (2008). General and Abdominal Adiposity and Risk of Death in Europe. New England Journal of Medicine, 359 (20), 2105-2120. doi: 10.1056/nejmoa0801891

[15] Bradshaw, P. T., Monda, K. L., Stevens, J. (2013). Metabolic syndrome in healthy obese, overweight, and normal weight individuals: The atherosclerosis risk in communities study. Obesity, 21 (1), 203-209. doi: 10.1002/oby.20248

[16] Milicya, K. M., Lavrik, A. S., Lavrik, O. A. (2016). Omentektomiya kak citoreduktivnyy etap lecheniya metabolicheskogo sindroma pri simul'tannyh operaciyah. Hirurgiya Ukrainy, 4 (60), 49-54.

[17] Coomarasamy, A., Shafi, M. I., Davila, G. W., Chan, K. K. (2016). Omental Procedures: Supracolic Omentectomy, Infracolic Omentectomy, Omental Biopsy. Gynecologic and Obstetric Surgery, 423-424. Available at: http://onlinelibrary.wiley.com/doi/10.1002/9781118298565.ch141/summary doi: 10.1002/9781118298565.ch141

[18] Herrera, M. F., Pantoja, J. P., Velazquez-Fernandez, D., Cabiedes, J., Aguilar-Salinas, C., Garcia-Garcia, E. et. al. (2010). Potential Additional Effect of Omentectomy on Metabolic Syndrome, AcutePhase Reactants, and Inflammatory Mediators in Grade III Obese Patients Undergoing Laparoscopic Rouxen-Y Gastric Bypass: A randomized trial. Diabetes Care, 33 (7), 1413-1418. doi: 10.2337/dc09-1833

[19] Milleo, F. Q., Campos, A. C. L., Santoro, S., Lacombe, A., Santo, M. A., Vicari, M. R. et. al. (2011). Metabolic effects of an entero-omentectomy in mildly obese type 2 diabetes mellitus patients after three years. Clinics, 66 (7), 1227-1233. doi: 10.1590/s1807-59322011000700018

[20] Boughton, B. (2011). Using Omentectomy With Gastric Bypass May Have Added Benefits. American Association of Clinical Endocrinologists (AACE) 20th Annual Meeting and Clinical Congress. Available at: http://www.medscape.com/viewarticle/741801 